\title{
Operational Impact of RES Penetration on a Remote Diesel-Powered System in West Papua, Indonesia
}

\author{
Maria Lorena L.Tuballa \\ School of Engineering, University of San Carlos \\ Cebu City, Philippines and College of Engineering \\ and Design, Silliman University, Dumaguete City, Philippines \\ mit_kin@yahoo.com
}

\author{
Michael Lochinvar S. Abundo \\ Nanyang Technopreneurship Centre, Nanyang Technological \\ University, Singapore and School of Engineering, \\ University of San Carlos, Cebu City, Philippines \\ michael.abundo@ntu.edu.sg
}

\begin{abstract}
When a new power source connects to the distribution or transmission grid, an assessment of its impact is necessary. Technical studies must assess the possible effects of a proposed expansion, reinforcement or modification to evaluate the possible incidents that may occur. Typically, the calculations or analyses done are load flow, short-circuit, and transient stability. The possible renewable energy (RE) sources are determined first. The details of the existing electrical system, including the specifications for the elements used, are obtained and logical assumptions are utilized for those that are not known. The load flow analysis in the considered case revealed that the RE presence reduces diesel generation. The $119 \mathrm{~kW} P V$ array and the $54 \mathrm{~kW}$ tidal turbine displace most diesel generation: $22 \%$ of Gen 4 and $21.8 \%$ of Gen 5 . The diesel-solar system brought the diesel generation down by $20.05 \%$ of Gen 4 and $20 \%$ of Gen 5 . The diesel-tidal combination lessened the diesel generation by $1.92 \%$ of Gen 4 and $1.83 \%$ of Gen 5 . Short-circuit analysis alerts indicating the operating percentages of the circuit breakers that are beyond their interrupting ratings are presented. The transient stability analysis depicts that $R E$ sources affect the existing system and appear to be putting in more stress. The studied systems are not transient-stable based on the results. While it is relatively simple to plan to put up renewables in remote island systems, there are many factors to consider such as the possible impacts of the RE sources.
\end{abstract}

Keywords-electrical grid; renewable energy; transient stability; diesel generation; tidal turbine

\section{INTRODUCTION}

In a typical distribution system, where a traditional electric grid that interconnects smaller grids is available, whenever a new significant power generation source connects to the distribution or transmission grid, whether it is conventional or a renewable energy (RE) resource, a grid impact assessment or grid impact study is necessary. These are sets of technical studies used to assess the possible effects of the proposed expansion, reinforcement, or modifications to evaluate the possible incidents that may occur. Power system issues are mostly dependent on system size, geographical distribution, planned capacities of variable renewable resources, system operation scheme, market structure, size of the balancing area and interconnection capacity. Typically, the calculations or analyses done on a grid impact study are load flow, short- circuit and transient stability studies. For remote islands that are not connected to the usual grid system, it is also rather important to see the impact of a new generation. The objective of the current study is to assess the impacts of solar energy, wind energy and tidal energy system on the operational characteristics of an electrical system powered only by diesel generators.

The specific location in Indonesia is PT Bintuni Utama Murni Wood Industries (PT BUMWI), a mangrove processing and woodchip plant. The company specializes in mangrove utilization and forest management. It started as a primary supplier of mangrove logs to the Japanese paper industry. The concession area is in Pulao Amutu Besar, Bintuni Bay, West Papua, with a total area of 82,120 hectares. The site activities include harvesting mangrove logs and processing them to make woodchips. The wood chip factory is located in the southern part of the island, with no available conventional electricity grid, thus the energy demand is met by off-grid diesel generators. The diesel fuel supply comes from Sorong, approximately $500 \mathrm{~km}$ away from the island. The reported high fuel cost is around 13,000 IDR (\$0.89 USD) per liter and base consumption for power generation is around 220,600 liters per year. The company aims to lessen its dependence on diesel fuel and achieve a sustainable power system by integrating RE. It plans to include tidal energy in its supply as the site is surrounded by a large bay.

\section{WEST PAPUA WOODCHIP FACTORY SITE}

Indonesia is an archipelago and the Indonesian transmission network is segregated into many power grids - eight interconnected networks and isolated grids that are all operated by PLN, a government-owned monopoly on electricity distribution in Indonesia. PLN prioritizes the development of renewable resources to supply local grids where available and interconnects grids where feasible [1]. PLN operates a total of 4600 diesel systems outside Java-Bali and approximately, there are 30.000 small diesel generator sets in the rural areas [2]. Indonesia's latest electricity ratio is approximately $86 \%$ and at present, its total plant capacity is $54 \mathrm{GW}, 17 \%$ of which come from New and Renewable Energy (NRE) sources. By 2025 total plant capacity is expected to grow to $115 \mathrm{GW}$ and NRE contribution to increase to $37 \%$ [3]. As of 2014, the electricity 
ratio targets reflect Papua as needing most of the capacity additions [4].

\section{A. The Existing Electrical System}

The PT BUMWI electrical plant houses five generator sets which supply power to the camp. The main loads are three $220 \mathrm{~kW}$ three-phase wood chipper machines. Other loads include residential, workshop, bulldozer rooms, conveyor belts, and ship loading.

\section{B. Solar Resource}

Indonesia, like any tropical country and being located in the equatorial line has abundant solar energy potential. The Indonesian energy potential for solar averages at 4.8 $\mathrm{kWh} / \mathrm{m}^{2} /$ day [5]. The PT BUMWI site is located at $02^{\circ} 31^{\prime} 11^{\prime \prime}$ $\mathrm{S}$ and $133^{\circ} 35^{\prime} 48^{\prime \prime}$ E. HOMER, a microgrid optimization software, provides average horizontal global solar radiation, expressed in $\mathrm{kWh} / \mathrm{m}^{2}$, for each hour of the year by specifying the coordinates of the site. Table I shows the representative clearness indices and daily radiation for the different months of the year while Figure 1 illustrates the global solar radiation

TABLE I. SITE CLEARNESS INDICES AND DAILY RADIATION

\begin{tabular}{|c|c|c|}
\hline Month & Clearness Index & Daily Radiation $\left.\mathbf{( k W h} / \mathbf{m}^{\mathbf{2}} \mathbf{d}\right)$ \\
\hline January & 0.489 & 5.04 \\
\hline February & 0.493 & 5.2 \\
\hline March & 0.482 & 5.07 \\
\hline April & 0.508 & 5.12 \\
\hline May & 0.531 & 5.01 \\
\hline June & 0.511 & 4.62 \\
\hline July & 0.488 & 4.48 \\
\hline August & 0.479 & 4.67 \\
\hline September & 0.479 & 4.93 \\
\hline October & 0.497 & 5.2 \\
\hline November & 0.514 & 5.3 \\
\hline December & 0.491 & 5 \\
\hline
\end{tabular}

\section{Wind Resource}

In general, a $2 \mathrm{~m} / \mathrm{s}$ minimum is required to start rotating most small wind turbines and the typical cut-in speed (when a small turbine starts generating power) is $3.5 \mathrm{~m} / \mathrm{s}$, with $10-15$ $\mathrm{m} / \mathrm{s}$ speeds producing maximum generation power [6]. The average recorded wind speed here is $2.32 \mathrm{~m} / \mathrm{s}$. Although this meets the minimum speed required to start rotating most small wind turbines, the typical cut-in speed of $3.5 \mathrm{~m} / \mathrm{s}$, occurs only around $7 \%$ of the time [7]. Figure 2 shows the wind rose. This limitation makes wind turbine generation at PT BUMWI impractical.

\section{Tidal Resource}

Tidal stream energy is a form of energy arising from the movement of masses of water or tides. Certain types of tidal stream generators or tidal turbines function similarly to wind turbines, with the only difference that they are underwater. The PT BUMWI site is situated near a strait, pointing to some good tidal in-stream resource in the area. The assessment of the tidal resource potential in the PT BUMWI factory was made by OceanPixel, a spin-off of Nanyang Technological University dedicated to increasing the ocean renewable energy uptake in South East Asia. The technical report [8] data are taken into account in the current study. Bathymetrical data is collected using an echo sounder. The bathymetry is computed by interpolating the combined data sets of the Indonesian Nautical Maps and the collected depth data. Tidal flows and velocities are determined using an Acoustic Doppler Current Profiler (ADCP). The recorded maximum current speed is $1.6 \mathrm{~m} / \mathrm{s}$ while the average current speed flowing through the center of the narrow strait in PT BUMWI is $0.7625 \mathrm{~m} / \mathrm{s}$. From the assessment, the monthly available resource is roughly 1.733 GWh. Table II shows the monthly speed averages of the projected tidal resource.

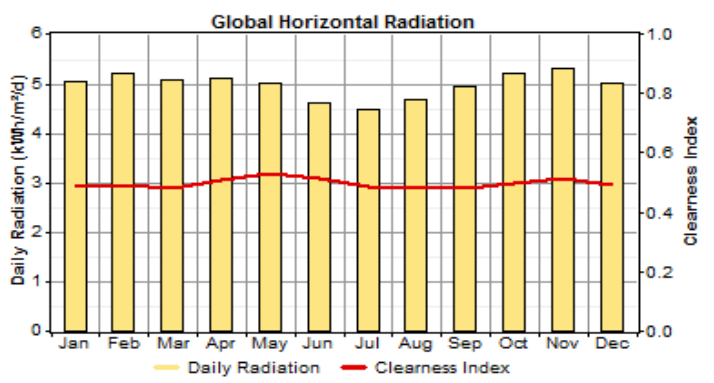

Fig. 1. Plot of PT BUMWI solar radiation

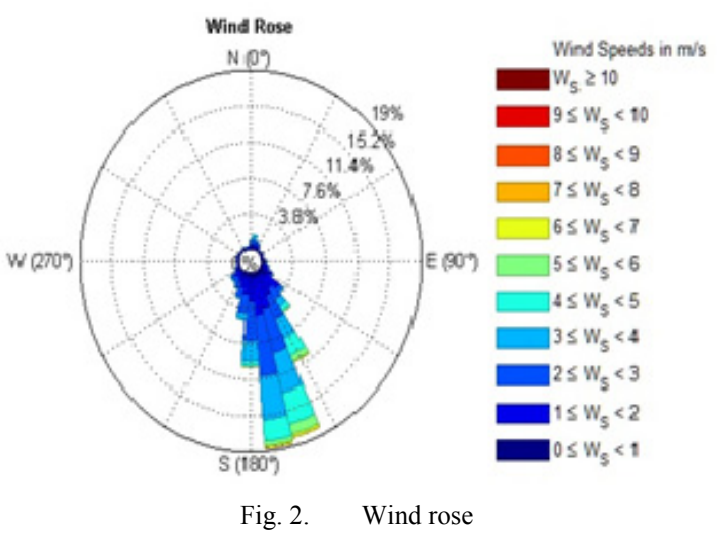

\section{E. Modeling Parameters}

The diesel generators are modeled based on their specifications. Details that are not known or specified are left as default values. Wood chippers are modeled as induction motors, corresponding to nameplate ratings. Other loads are modeled as lumped loads. Ratings for the lumped loads require real and reactive power components and these are taken from energy loggers deployed on their respective panels on site. The capacitor banks in PT BUMWI consists of six parallel threephase capacitors, each rated $23.2 \mathrm{kVAR}$. The inputs are taken from PhMKP440.3.28, 10-84 LVAC Power Capacitors data sheet, the capacitors installed in the site. Whenever solar panels are involved in ETAP, there is an option to calculate the irradiance for a specified location. In this case, it is $1.3361^{\circ} \mathrm{S}$, $133.1747^{\circ}$ E. Figure 3 shows the irradiance calculator and the $\mathrm{PV}$ array editor configurations used. The tidal turbine is not an 
available element in ETAP, hence the tidal turbine is modeled as a Wind Turbine Generator. The characteristics of the Schottel In-stream Turbine are used for the wind turbine inputs and specified according to the actual type that would be running with the diesel generators in PT BUMWI. In a separate microgrid simulation, the suggested optimal size for the tidal turbine is $54 \mathrm{~kW}$. Figure 4 shows the Info and Turbine specifications tabs.

TABLE II. MONTHLY TIDAL CURRENT SPEED AVERAGES

\begin{tabular}{|c|c|}
\hline Month & Tidal Speed $(\mathbf{m} / \mathbf{s})$ \\
\hline January & 1.042 \\
\hline February & 0.909 \\
\hline March & 0.956 \\
\hline April & 1.019 \\
\hline May & 1.03 \\
\hline June & 0.96 \\
\hline July & 0.894 \\
\hline August & 0.933 \\
\hline September & 0.891 \\
\hline October & 0.969 \\
\hline November & 1.031 \\
\hline December & 1.044 \\
\hline
\end{tabular}

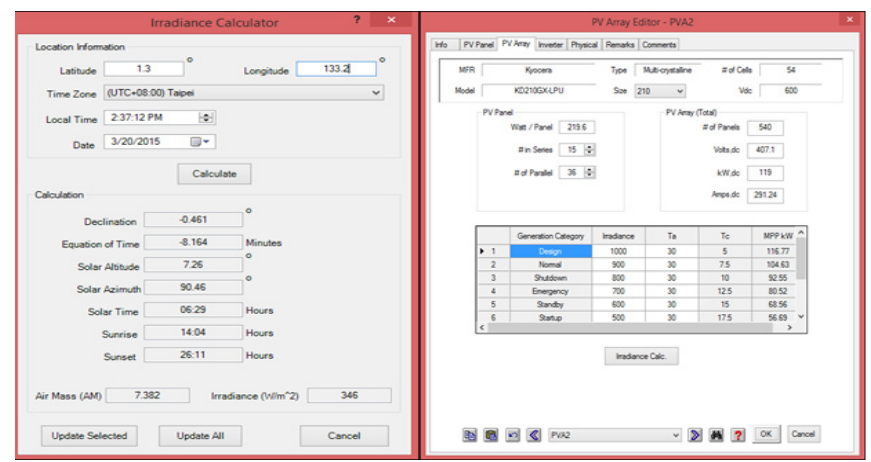

Fig. 3. Irradiance Calculator and PV Array Editor

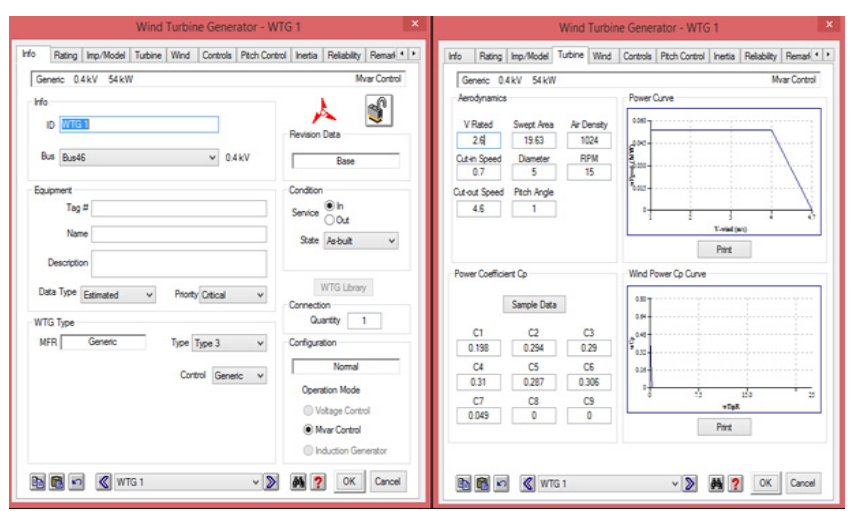

Fig. 4. Tidal turbine info and ratings tabs (modeled as wind turbine)

\section{RESULTS AND DISCUSSION}

In Figure 5 the simplified single-line diagram of the PT BUMWI electrical system implemented in ETAP is shown. It consists of 7 buses, 15 branches, 5 diesel generators (two running diesel generators at a time, usually Gen 4 and Gen 5), 9 different connected loads and 6 capacitors each rated 23.2 kVAR.

\section{A. Load Flow Study}

Load flow studies aim to determine whether an existing or reinforced system can satisfy the voltage and current limits, under steady-state conditions. It must be seen that the loading levels of all transmission lines and substation equipment are below $90 \%$ of the maximum continuous ratings of phase conductors and transformers. Deviations may only be acceptable on the contingency that depends on the condition of the facility. Voltage variations in the system for all voltage levels shall remain within $\pm 5 \%$ of the nominal value during normal conditions and during single outage contingency events. The load flow results are obtained for different configurations: existing diesel system, diesel-solar system and diesel-tidal system and diesel-solar-tidal system. There are no significant issues found in the load flow. The presence of the $\mathrm{RE}$ reduces the percent generation of the diesel generators, with the diesel-solar-tidal displacing the most diesel generation: $22 \%$ of Gen 4 and $21.8 \%$ of Gen 5 . The diesel-solar system brought the diesel generation down to $20.05 \%$ of Gen 4 and $20 \%$ of Gen 5 . The diesel-tidal combination lessened the diesel generation by $1.92 \%$ of Gen 4 and $1.83 \%$ of Gen 5 . The dieselsolar-tidal would have displaced only roughly $6 \%$ of Gen 4 's generation and $6.1 \%$ of Gen 5's generation if the solar PV were sized to match the tidal turbine. The load flow studies for the other configurations do not reflect any voltage issue. Table III displays the Load Flow Analyzer Results.

TABLE III. LOAD FLOW ANALYZER RESULTS

\begin{tabular}{|c|c|c|c|}
\hline System & ID & \% PF & \% Generation \\
\hline \multirow{2}{*}{ Diesel } & Gen 4 & $83.48 \%$ & $36.4 \%$ \\
\cline { 2 - 4 } & Gen 5 & $83.48 \%$ & $65.5 \%$ \\
\hline \multirow{2}{*}{ Diesel-Solar } & Gen 4 & $77.14 \%$ & $29.1 \%$ \\
\cline { 2 - 4 } & Gen 5 & $77.14 \%$ & $52.4 \%$ \\
\hline \multirow{3}{*}{ Diesel-Tidal } & Gen 4 & $85.51 \%$ & $35.7 \%$ \\
\cline { 2 - 4 } & Gen 5 & $85.51 \%$ & $64.3 \%$ \\
\cline { 2 - 4 } & WTG1 & $77.14 \%$ & $16.9 \%$ \\
\hline \multirow{3}{*}{ Diesel-Solar-Tidal } & Gen 4 & $79.55 \%$ & $28.4 \%$ \\
\cline { 2 - 4 } & Gen 5 & $79.55 \%$ & $51.2 \%$ \\
\cline { 2 - 4 } & WTG1 & $77.14 \%$ & $16.9 \%$ \\
\hline
\end{tabular}

\section{B. Short Circuit Study}

Short circuit studies determine the magnitude of currents that flow through electrical faults and compare these against the ratings of the equipment to ensure that proper protection is present. Short-circuit levels through all circuit breakers have to be within acceptable limits not just to prevent costly replacement projects but to ensure safety to equipment and personnel. In addition to the short-circuit study, a protectioncoordination can be done to determine the trip settings of the protective devices in the system in order to achieve maximum protection with minimum interruption for all faults that can possibly occur. In this study, protection coordination is not covered. The majority of fault studies include only three-phase and single line-to-ground faults. Three-phase faults, though they rarely occur (around 5\% of initial faults) are usually the most severe. On the other hand, single line-to-ground faults are 
the most common $(80 \%)$. The rest are either line-to-line or lineto-line-to-ground faults. The Short-circuit analysis program in ETAP enables the analysis of the effect of different types of faults such as 3-phase, line-to-ground, line-to-line, and line-toline-to-ground faults on distribution systems. The program calculates total short-circuit currents and the contributions of individual motors, generators, and utility ties in the system. Fault duties are in compliance with the latest editions of the ANSI/IEEE Standards and IEC Standards. Table IV gives the short circuit analysis results.

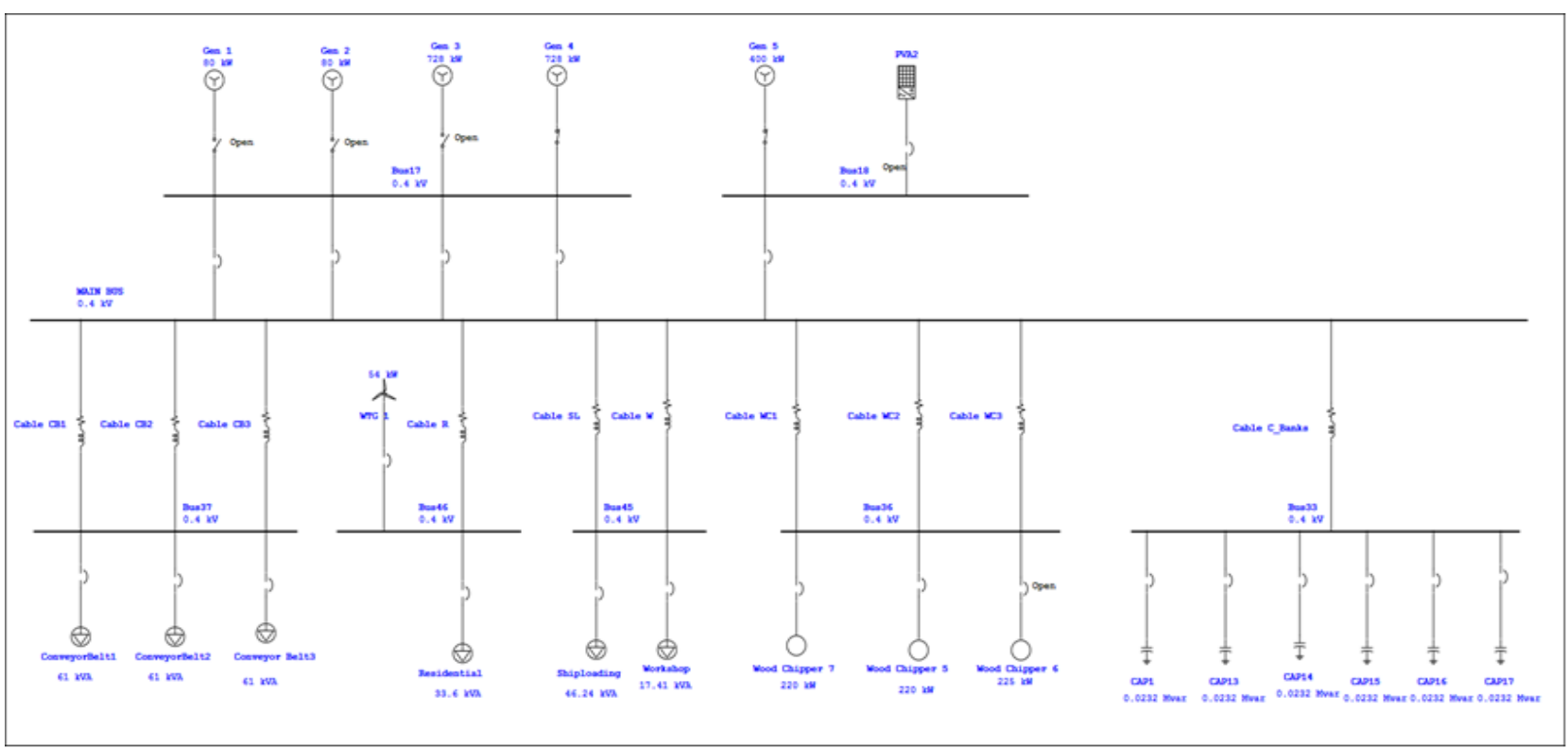

Fig. 5. The PT BUMWI Single-line Diagram in ETAP

TABLE IV. SHORT CIRCUIT ABALYSIS RESULTS

\begin{tabular}{|c|c|c|c|c|}
\hline $\begin{array}{c}\text { Faulted } \\
\text { Bus }\end{array}$ & $\begin{array}{c}\text { System } \\
\text { (No RE) }\end{array}$ & $\begin{array}{l}\text { System } \\
\text { (Solar) }\end{array}$ & $\begin{array}{c}\text { System } \\
\text { (TD) }\end{array}$ & $\begin{array}{c}\text { System } \\
\text { (Solar and } \\
\text { TD) }\end{array}$ \\
\hline \multicolumn{5}{|c|}{ Bus 17} \\
\hline 3-Phase & CBG1-4 & CBG1-4 & CBG1-4 & CBG1-4 \\
\hline Faults - & Operating & Operating & Operating & Operating \\
\hline Device Duty & $217.5 \%$ & $160.2 \%$ & $220.4 \%$ & $162.6 \%$ \\
\hline \multicolumn{5}{|c|}{ Bus 18} \\
\hline & & CB PVA & & CB PVA \\
\hline 3-Phase & CBG5 & Oparating & CBG5 & Oparating \\
\hline Faults - & Operating & $192.2 \%$ & Operating & $195.1 \%$ \\
\hline Device Duty & $217.5 \%$ & CBG5 & $220.4 \%$ & CBG5 \\
\hline & & $\begin{array}{c}\text { Operating } \\
160.2 \% \\
\end{array}$ & & $\begin{array}{c}\text { Operating } \\
162.6 \%\end{array}$ \\
\hline \multicolumn{5}{|c|}{ MAIN BUS } \\
\hline 3-Phase & CBG1-5 & CBG1-5 & CBG1-5 & CBG1-5 \\
\hline Faults - & Operating & Operating & Operating & Operating \\
\hline Device Duty & $217.5 \%$ & $160.2 \%$ & $220.4 \%$ & $162.6 \%$ \\
\hline \multicolumn{5}{|c|}{ Bus 46} \\
\hline & No Alert & No Alert & No Alert & No Alert \\
\hline \multicolumn{5}{|c|}{ Bus 36} \\
\hline 3-Phase & CB WC1-2 & CB WC1-2 & CB WC1-2 & CB WC1-2 \\
\hline Faults - & Operating & Operating & Operating & Operating \\
\hline Device Duty & $280.4 \%$ & $173.9 \%$ & $175.7 \%$ & $175 \%$ \\
\hline \multicolumn{5}{|c|}{ Bus 33} \\
\hline 3-Phase & CB CAP1- & CB CAP1-6 & CB CAP1-6 & CB CAP1-6 \\
\hline Faults - & $\begin{array}{c}6 \\
\text { Onerating }\end{array}$ & Operating & Operating & Operating \\
\hline Device Duty & $\begin{array}{c}\text { Operating } \\
132.6 \%\end{array}$ & $132.2 \%$ & $133.2 \%$ & $132.8 \%$ \\
\hline
\end{tabular}

\section{Transient Stability}

Transient stability is the ability of the system to maintain synchronism when subjected to a severe fault or disturbance. Generators and large machines connected to the system should remain in synchronism and maintain stable operation during normal and during contingency events. The fault clearing times must be adequate and breakers need to trip or be manually tripped before any catastrophic event occurs. The clearing time used was 0.08 seconds, ( 4 cycles) [9]. A threephase fault was assumed to have occurred in Bus 18 at 1.000 $\mathrm{sec}$ and cleared at $1.080 \mathrm{sec}$, with a 20 -second simulation time. Figure 6 shows the details of the transient stability study case. Some of the transient stability plots for the two diesel generators, the loads and the buses are shown below. In Figure 7 , the generator reactive power has hugely defined peaks and dips and highly frequent changes in amplitudes in the presence of the RE sources. The case looks worse in the diesel-solar system. Figure 8 shows the load reactive power plot in the diesel-generator system. When the system is run by diesel alone, these parameters show some degree of stability, but not totally as load reactive power is not the same as the reactive power after fault clearing. The generator electrical power plots are shown in Figure 9. They display similar behavior with that observed in Figure 7. These almost noise-like plots need the more attention. 


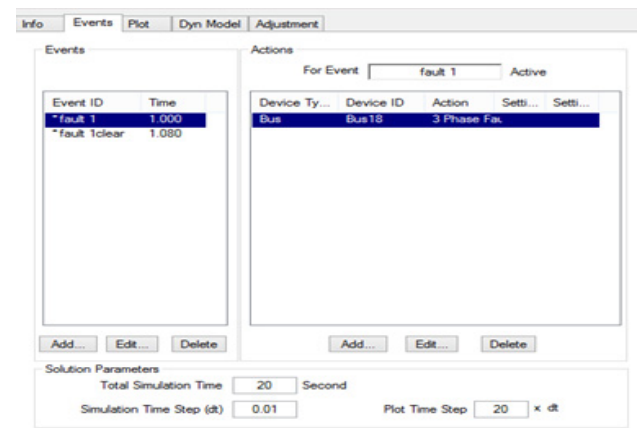

Fig. 6. Transient stability study case details

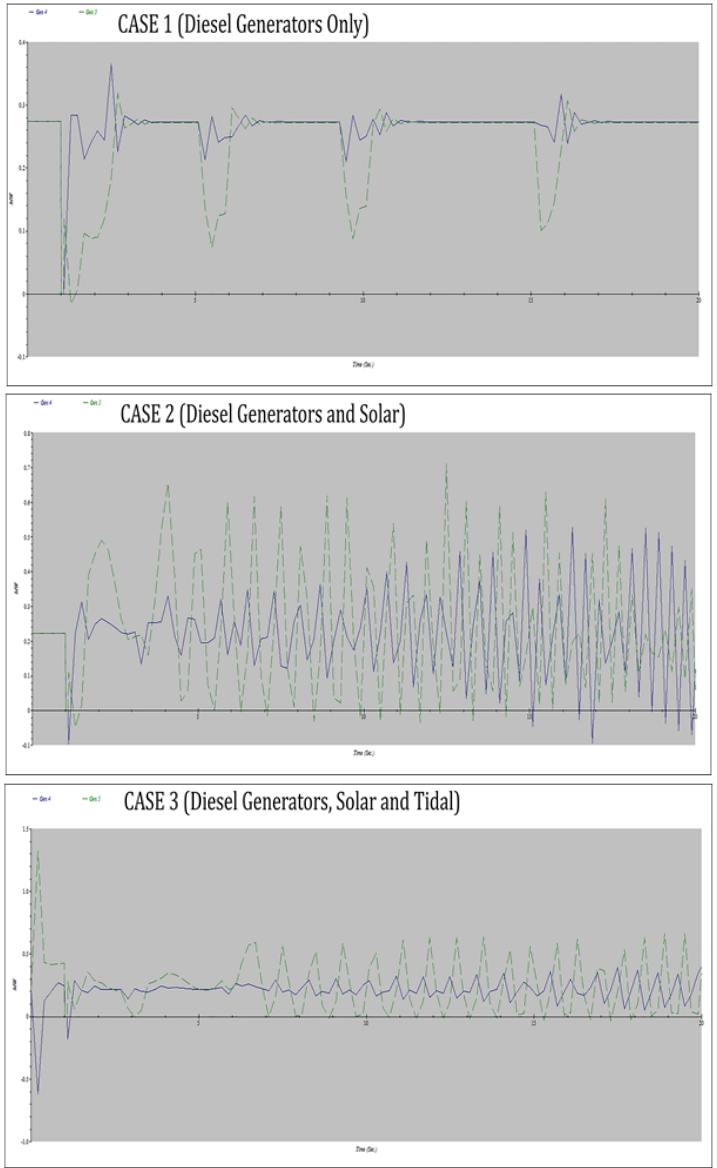

Fig. 7. Generator reactive power

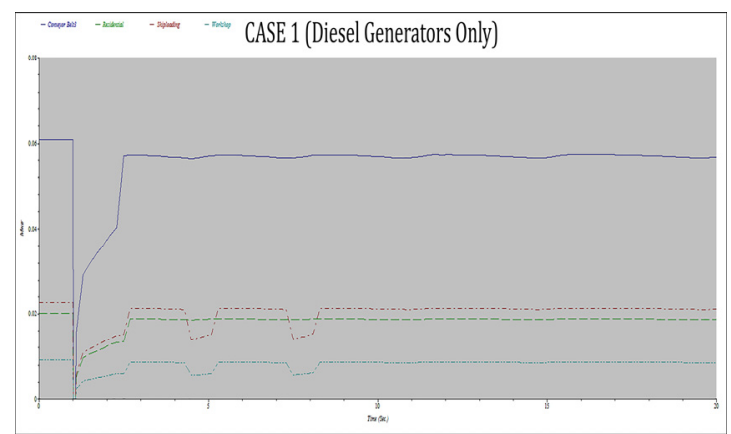

Fig. 8. Load reactive power (diesel only)
Fluctuations in the load reactive power and load electrical power are also observed in the presence of the RE sources. Figure 10 exhibits the behavior of the bus frequency in the diesel, solar and tidal configuration. It shows the worst among the three simulated systems. As to the generator speed, variation is most unfavorable in the diesel-solar configuration. Figure 11 shows the generator speed variations after the fault clearing-when the system is powered by diesel, by diesel and solar and by the diesel, solar and tidal combination. The plots illustrate that after fault clearing, the generators, buses and load parameters do not return to their original state.

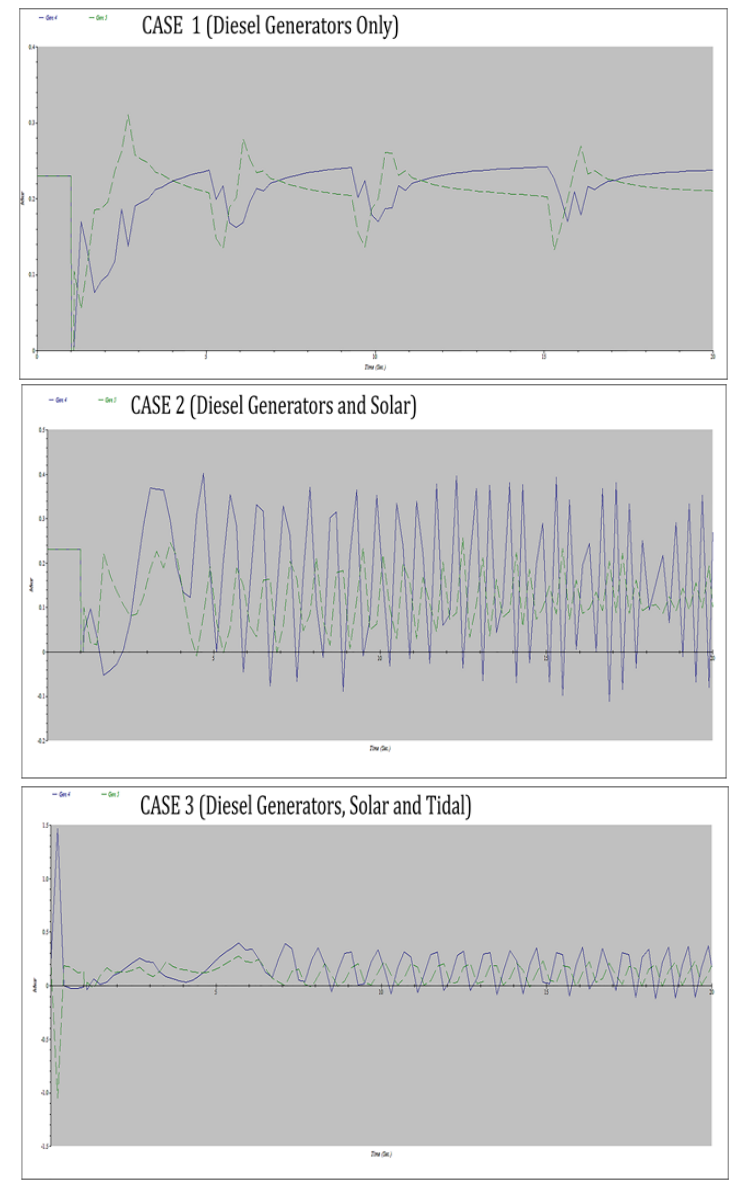

Fig. 9. Generator electrical power

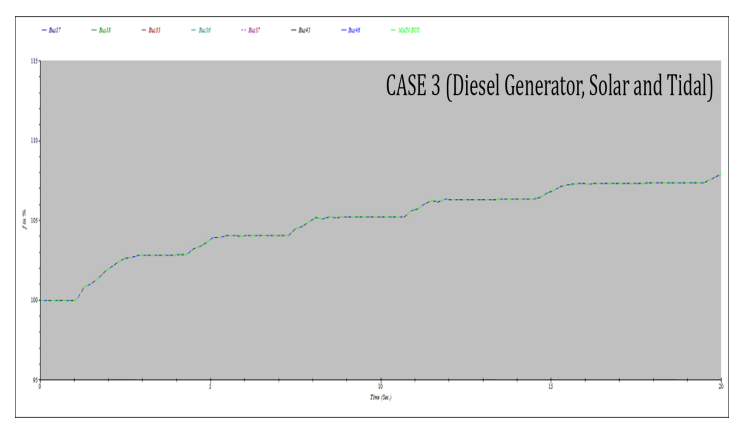

Fig. 10. Bus frequency 


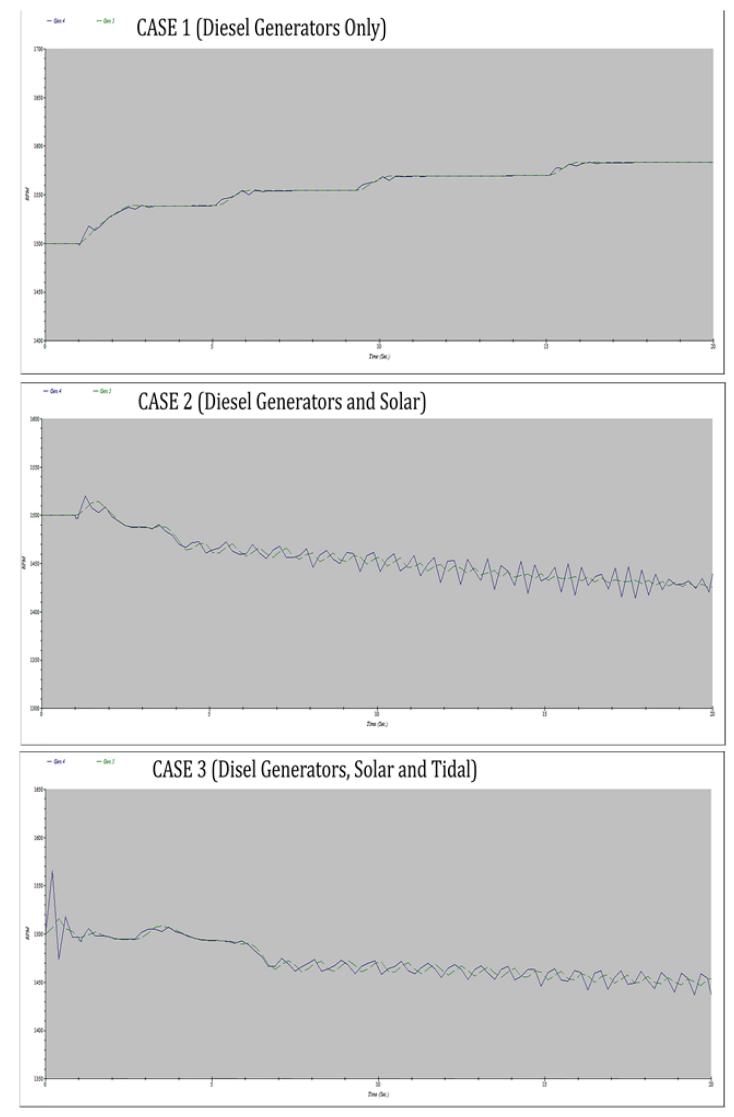

Fig. 11. Generator speed

\section{CONCLUSION}

This study gives an insight on the operational impacts of $\mathrm{RE}$ on an island grid. The load flow analysis revealed that the RE presence reduces the diesel generation. The $119 \mathrm{~kW}$ PV array and the $54 \mathrm{~kW}$ tidal turbine (here simulated as a wind turbine generator) displace the most diesel generation: $22 \%$ of Gen 4 and $21.8 \%$ of Gen 5 . The diesel-solar system diesel generation brought the diesel generation down by $20.05 \%$ of Gen 4 and $20 \%$ of Gen 5. The diesel-tidal combination lessened the diesel generation by $1.92 \%$ of Gen 4 and $1.83 \%$ of Gen 5. The short-circuit analysis alerts indicate the operating percentages of the circuit breakers that are beyond their interrupting ratings. Since the circuit breaker ratings are assumed, before actual replacements and/or modifications are done, the models of these protective devices need to be identified and data inputs changed accordingly. The transient stability analysis depicts that the intermittency of the RE sources affects the existing system and appears to be putting in more stresses. The systems in the study are not transient-stable

\section{ACKNOWLEDGMENT}

Authors would like to thank Engineering Research for Development and Technology (ERDT), OceanPixel Pte. Ltd. and Green Forest Product \& Tech. Pte. Ltd.

\section{REFERENCES}

[1] P. Tharakan, Summary of Indonesia's Energy Sector Assessment, ADB, 2015

[2] S. Blocks, "Business assessment for diesel hybrid systems in Indonesia, German-Indonesian Chamber of Industry and Commerce, 2013

[3] Ministry of Energy and Mineral Resources Republic of Indonesia, Indonesia's Renewable Energy and Energy Conservation Development, 2015

[4] Pwc, Power in Indonesia- Investment and Taxation Guide, 2017

[5] Unep Dtu Partnership, Indonesian Solar Pv Rooftop Program (ISPRP)Facilitating Implementation and Readiness for Mitigation (FIRM), 2016

[6] BRANZ Ltd., "Wind turbine systems", available at: http://www.level.org.nz/energy/renewable-electricity-generation/windturbine-systems/, 2017

[7] J. Valleser, "A Techo-Economic Feasibility Study of Implementing a Hybrid Renewable Energy Microgrid at PT BUMWI Camp, Amutu Besar, Bintuni Bay, Indonesia”, University of San Carlos, 2016

[8] Ocean Pixel, Tidal In-Stream Energy Resource Assessment in Bintuni Bay, West Papua, Indonesia, 2015

[9] D. K. Neitzel, "Protective Devices Maintenance as it Applies to the Arc/Flash Hazard", Conference Record of the 2004 Annual Pulp and Paper Industry Technical Conference, IEEE, pp. 209-215, 2004 